\title{
VII. Die Mittheilungen von Brown-Séquard und d'Arsonval über die Toxicität der Exspirationsluft.
}

Nach den Comptes rendus der Akademie und der Société de Biologie referirt von Carl Günther.

Am 28. November 1887 theilten B rown-Séquard und d'Arsonval der Akademie des sciences in Paris mit, dass Thiere, die sie mit tnberculösem Virns geimpft hätten, gesnnd geblieben seien, wenn dieselben in frischer Lnft gehalten worden wären, dass sie aber beim Anfenthalt in eng begrenzten Ränmen an Tuberculose erkrankt nnd gestorben seien. Die Antoren halten dafür, dass bei dem Znstandekommen der Lungentuberculose überhanpt die Exspirationslnft, die im geschlossenen Raume immer wieder eingeathmet wird, eine wesentliche Rolle spielt. Am 9. Jannar 1888 ergänzten Brown.-Séquard und d'Arsonval ihre Mittheilnngen in ansgedehnter Weise. Sie hatten die Exspirationslnft (oder vielmehr den in derselben befindlichen Wasserdampf mit den in dem letzteren gelösten Substanzen) gesunder Menschen und Hunde condensirt, sie liatten ferner Thieren grössere Mengen reinen Wassers in die Lungen injicirt, von diesenı Wasser dann wieder etwas znrückgezogen; mit so ans der Lnuge erhaltenen Flüssigkeiten wnrden daun Hunden und Kaninchen Injectionen in die Blntgefässbahn gemacht. Bei Injection von 4--8 $\mathrm{ccm}$ zeigte sich leichte Pnpillenerweiternng, ferner Verlangsamnng der Respiration nnd paralytische Schwäche, besouders der hinteren Extremitäten, leichteTemperatnrerniedrignng. Wurden grössere Mengen $(20-25 \mathrm{ccm})$ der Flüssigkeit injicirt, so steigerten sich die genanuten Vergiftungserscheinnugen ; nuter Krämpfen, grosser Schwäche, choleraartigen Diarrhoeen gingen die Thiere hänfig in 3-4 Tagen zil Grnnde. Das Bewnsstsein war bis znm Tode erhalten. Bei der Antopsie fanden sich Blntfïlle der Organe nnd Ecchymosen. BrownSéquard und d'Arsouval ziehen ans diesen Beobachtungen den Schlnss, dass 1) die Lnugen des Menschen, des Hundes nud des Kaninchens im gesnnden Znstande ein änsserst energisches Gift prodnciren, welches mit der Exspirationslnft fortwährend ans der Lunge entfernt wird; 2) dass höchst wahrscheinlich, wenn nicht sicher, dieses toxische Agens den Anfenthalt in geschlossenen, nicht ventilirten Ränmen so gefährlich macht. Der Kohlensänregehalt der Exspirationslnft, ebenso wie der geringe Gehalt derselben an Ammoniak könne znr Erklärung der beobachteten Erscheinnngen nicht heran gezogen werden. - Am 16. Jannar d. J. fügten die Antoren dem bisher Mitgetheilten noch hinzn, dass das toxische Agens der Exspirationslnft ein flüchtiges organisches Alkaloid (ans der Reihe der Ptomaïne oder Lenkomaïne) sei. Die Flüssigkeit nåmlich, welche das Gift enthält, zeigt sich alkalisch; beim Anfkochen im geschlossenen Gefäss bleibt das Gift nnverändert. Die Antoren betonen wiederum ibre Ansicht, dass das Gift für die Entstehnug der Lnngentuberculose von Bedentnug sei. Es wirkt anf die Thiere bei intravasaler nnd subcntaner Einverleibnng, ebeuso aber, wenn es per rectnm oder per os dem Körper einverleibt wird. Die Antoren weisen anf die Aehnlichkeit in der Einwirknng zwischen ihrem Gifte nud dem von Brieger dargestellten Nenrin hin.

Die Mittheilnngen von Brown-Séquard und d'Arsonval haben Angriffe erfahren durch Dastre nud Loye, welche am 3 . Febrnar d.J. in der Société de Biologie eine Reihe von Versnchen mittheilen, welche die Resnltate der znerst genannten Antoren nicht bestätigten. Eine weitere Prüfnng des hochinteressanten Themas bleibt abzuwarten: 